\title{
Transactivation of miR-202-5p by Steroidogenic Factor 1 (SF1) Induces Apoptosis in Goat Granulosa Cells by Targeting TGF $\beta$ R2
}

\author{
Qiang Ding ${ }^{+} \mathbb{D}$, Miaohan Jin ${ }^{+}$, Yaoyue Wang, Jiao Liu, Peter Kalds, Ying Wang, Yuxin Yang, \\ Xiaolong Wang * and Yulin Chen *
}

Key Laboratory of Animal Genetics, Breeding and Reproduction of Shaanxi Province, College of Animal Science and Technology, Northwest A\&F University, Yangling 712100, Shaanxi, China; dingqiang@nwafu.edu.cn (Q.D.); jinmiaohan@nwafu.edu.cn (M.J.); 18792629437@163.com (Y.W.); liujiaodk@163.com (J.L.);

peterkalds@nwafu.edu.cn (P.K.); nd2013wang@163.com (Y.W.); yangyuxin2002@126.com (Y.Y.)

* Correspondence: xiaolongwang@nwafu.edu.cn (X.W.); chenyulin@nwafu.edu.cn (Y.C.)

+ These authors equally contribute to this paper.

Received: 16 December 2019; Accepted: 11 February 2020; Published: 14 February 2020

check for updates

\begin{abstract}
MicroRNAs play key roles during ovary development, with emerging evidence suggesting that miR-202-5p is specifically expressed in female animal gonads. Granulosa cells (GCs) are somatic cells that are closely related to the development of female gametes in mammalian ovaries. However, the biological roles of miR-202-5p in GCs remain unknown. Here, we show that miR-202-5p is specifically expressed in GCs and accumulates in extracellular vesicles (EVs) from large growth follicles in goat ovaries. In vitro assays showed that miR-202-5p induced apoptosis and suppressed the proliferation of goat GCs. We further revealed that miR-202-5p is a functional miRNA that targets the transforming growth factor-beta type II receptor (TGF $\beta R 2)$. MiR-202-5p attenuated TGF- $\beta / S M A D$ signaling through the degradation of TGF $\beta R 2$ at both the mRNA and protein level, decreasing p-SMAD3 levels in GCs. Moreover, we verified that steroidogenic factor 1 (SF1) is a transcriptional factor that binds to the promoters of miR-202 and cytochrome P450 family 19 subfamily A member 1 (CYP19A1) through luciferase reporter and chromatin immunoprecipitation (ChIP) assays. That contributed to positive correlation between miR-202-5p and CYP19A1 expression and estradiol (E2) release. Furthermore, SF1 repressed TGF $\beta$ R2 and p-SMAD3 levels in GCs through the transactivation of miR-202-5p. Taken together, these results suggest a mechanism by which miR-202-5p regulates canonical TGF- $\beta$ /SMAD signaling through targeting TGF $\beta 2$ in GCs. This provides insight into the transcriptional regulation of miR-202 and CYP19A1 during goat ovarian follicular development.
\end{abstract}

Keywords: miR-202-5p; TGF $\beta$ 2; TGF- $\beta$ signaling pathway; goat granulosa cell; cell apoptosis; SF1

\section{Introduction}

Female fecundity is closely related to follicular development in the ovaries of mammals. Primordial oocytes in the ovaries gradually increase in size ultimately forming mature oocytes and ovulate. However, less than $1 \%$ of the oocytes can cause ovulation [1-3] as most are wrapped in atretic follicles and are unable to ovulate. Accumulating evidence suggests that the initiation of follicular atresia is mainly due to granulosa cell (GC) apoptosis (programmed cell death) [4,5]. Ovarian endocrine factors have been extensively studied in GCs apoptosis, the regulation by small noncoding RNAs (microRNAs) has attracted more attention in recent years.

microRNAs (miRNAs) are 22 nucleotides in length, noncoding RNAs post-transcriptionally regulate gene expression through binding to partially complementary sites on the $3^{\prime}$-untranslated 
region (3'-UTR) of target mRNAs, resulting in mRNA degradation or inhibiting gene transcription. Dynamic changes in the levels of miRNA expression occur during ovarian development with different miRNA profiles existing [6,7]. To date, several miRNAs have been identified as regulators of GCs apoptosis in domestic animals, including miR-92a [8], miR-1275 [9], and let-7g [10]. Despite the identification of many candidate miRNAs, their biological functions in the ovaries remains unclear. MiRNA-mediated GCs apoptosis therefore requires further exploration.

In this study, we selected miR-202-5p for further studies based on its significant enrichment in the extracellular vesicles from follicular fluid in goat ovarian follicles. MiR-202-5p is a germ plasm unique miRNA that is abundantly enriched in the gonads of some mammals and lower vertebrates. In mouse, miR-202-5p is specifically expressed in the Sertoli cells of embryonic gonads [11] and in spermatogonial stem cells (SSCs) in the testis [12]. In human testis, miR-202-5p is a germ cell-dependent expressing miRNA in Sertoli cells [13], indicating its role in spermatogenesis. Moreover, miR-202 is conservatively expressed in the germ cells of lower vertebrates, such as frogs $[14,15]$ and fish. The expression of miR-202-5p gradually increases during zebrafish oocyte growth and peaks in mature oocytes [16]. MiR-202 silencing in medaka fish impairs early folliculogenesis, subsequently reducing the number of eggs leading to abnormal eggs that cannot be fertilized, leading to low-fecundity [17], implying a role for miR-202-5p during oogenesis. Previously studies reported that miR-202-5p is typically abundant in large animal ovarian follicles $[6,18,19]$, but its roles remained elusive. In this study, we investigated the expression of miR-202-5p in goat GCs of different follicle sizes and further demonstrate its biological functions. In addition, we confirmed a transcriptional target of miR-202 and reveal its specific roles in ovarian follicles. Therefore, we have identified that miR-202-5p might be a potential marker for ovulation in goats.

\section{Materials and Methods}

\subsection{Follicular Separation, Cell Isolation, and Culture}

Adult goat ovaries were collected at a slaughterhouse (Baoji, Shaanxi, China) and transported to the laboratory at $\sim 4{ }^{\circ} \mathrm{C}$ in $0.9 \%$ physiological saline solution. Ovaries were selected based on the presence of at least one obvious large follicular follicle at the ovarian surface.

Goat ovarian follicles were dissected and sorted according to their diameter (small follicles $<3 \mathrm{~mm}$ and large follicles $>5 \mathrm{~mm}$ ). GCs, cumulus oocyte complexes (COCs), and naked-oocytes were squeezed from the 2-5 mm diameter goat follicles of mature ovaries using $1 \mathrm{~mL}$ syringes. COCs and naked oocytes were sorted using mouth pipettes. GCs were seeded into 24 -well culture plates at a density of $1 \times 10^{6}$ cells and cultured in a serum-free medium containing sodium bicarbonate $(10 \mathrm{mmol} / \mathrm{L})$, sodium selenite ( $4 \mathrm{ng} / \mathrm{mL})$, bovine serum albumin (BSA) (0.1\%; Sigma-Aldrich, Saint Louis, MO, USA), penicillin $(100 \mathrm{U} / \mathrm{mL})$, streptomycin $(100 \mu \mathrm{g} / \mathrm{mL}), 1 \times$ ITS-A (Insulin-Transferrin-Selenium-Sodium Pyruvate (ITS-A) (100×), 51300044, ThermoFisher Scientific, Green Island, NY, USA), nonessential amino acid mix $(1.1 \mathrm{mmol} / \mathrm{L})$, androstenedione $\left(10^{-7} \mathrm{M}\right.$ at start of culture and $10^{-6} \mathrm{M}$ at each medium change) and bovine follicle-stimulating hormone (FSH) $(10 \mathrm{ng} / \mathrm{mL}$ starting on day 2; AFP5346D; National Hormone and Peptide Program, Torrance, CA, USA). GCs were maintained in $5 \% \mathrm{CO}_{2}$ at $37^{\circ} \mathrm{C}$ for $4 \mathrm{~d}$ prior to treatment and replaced with a $70 \%$ medium every $48 \mathrm{~h}$. COCs and naked oocytes were collected and frozen at $-70^{\circ} \mathrm{C}$.

\section{2. $R N A$ Isolation and $q P C R$}

Total RNAs were extracted from ovarian follicles, COCs, naked oocytes, cultured GCs, and follicles fluid EVs using RNAiso (TaKaRa, Dalian, China) based on the manufacturer's protocols. Total RNAs were reverse transcribed using First Strand cDNA synthesis kits (ThermoFisher Scientific, USA). Using specific miRNA reverse primers, the stem-loop method was used for miRNA synthesis. Relative mRNA expression was measured with qPCR using SYBR Premix EX Taq II (TaKaRa, Dalian, China). PCRs were performed in triplicate. GAPDH was used as internal control for mRNA, with U6 used 
for miRNA. The $2^{-\Delta \Delta C t}$ method was used to normalize the relative expression levels of the target genes [20]. Primers sequences are shown in Supplementary Table S1.

\subsection{Small RNAs Sequencing of FF-EVs}

Total RNA was evaluated with an Agilent 2100 Bioanalyzer (Agilent Technologies, Santa Clara, CA, USA). RNA concentrations were measured using Qubit ${ }^{\circledR}$ RNA assay kits in a Qubit ${ }^{\circledR} 2.0$ Flurometer (Life Technologies, Eugene, OR, USA). A total of $20 \mathrm{ng}$ of small RNA per exosome was used for the construction of small RNA sequencing libraries. Each sample library was built following the manufacturer's recommendations of NEBNext ${ }^{\circledR}$ Multiplex Small RNA Library Prep Set for Illumina ${ }^{\circledR}$ (NEB, Ipswich, MA, USA). All libraries were sequenced on an Illumina Hiseq 2500 platform and $50 \mathrm{bp}$ single-end reads were generated. MiRNA expression levels were estimated by transcript per million (TPM) as described [21]: Normalized expression = mapped read count/total reads $\times 1,000,000$. Differential miRNA expression across the two EVs groups were performed using the DESeq $\mathrm{R}$ package [22]. $p$-values were adjusted using $\mathrm{q}$-values; $\mathrm{q}$-value $<0.01$, and $\mid \log 2$ (fold change) $\mid>1$ were set as the threshold for significantly differential expression.

\subsection{Plasmids and siRNAs}

PcDNA3.1(+)-neo, pGL3-basic, pRL-TK, and psiCheck ${ }^{\mathrm{TM}}-2$ vectors were kindly provided by Wenxian Zeng's laboratory (College of Animal Science and Technology, Northwest A \& F University, China). The promoter region of CYP19A1 or miR-202 were amplified from the total DNA of goat GCs and subcloned into the pGL3-basic for luciferase assays. Partial sequences of the TGF $\beta R 23^{\prime}$-UTR regions (containing miR-202-5p binding sites) were amplified from the cDNA of goat GCs and subcloned into psiCheck ${ }^{\mathrm{TM}}-2$. Overlap PCRs were performed to generate mutant plasmids and successful mutations were identified by Sanger sequencing. For overexpression studies, CDS fragments of SF1 and TGF $\beta R 2$ were amplified from GC cDNA and subcloned into pcDNA3.1(+)-neo. MiR-202-5p mimics, miR-202-5p inhibitors, mimic NC, inhibitor NC, SF1-siRNA, TGF $\beta R 2$-siRNA, and siRNA-NC were chemically synthesized by Shanghai GenePharma (Shanghai, China). SiRNA sequences are listed in Supplementary Table S2.

\subsection{Cell Transfection}

GCs were cultured in a fresh medium prior to DNA or RNA transfection. MiRNAs, plasmids, and siRNAs were transfected into cells using Lipofectamine ${ }^{\circledR} 3000$ (ThermoFisher Scientific, CA, USA) according to the manufacturer's instructions. Cells were harvested for RNA or protein extraction 72 $\mathrm{h}$ post-transfection.

\subsection{Estradiol ELISA Assay}

Follicular fluid (FF) was isolated from the follicles. Samples were centrifuged for $10 \mathrm{~min}$ at $3000 \mathrm{rpm}$ to remove cells and cellular debris. The concentration of estradiol in the FF was measured using a Goat estrogen ELISA kit (Shanghai Meilian Biotechnology Company, Shanghai, China) according to the manufacturer's protocols.

\subsection{Western Blotting (WB)}

The EVs of FF were purified by differential ultracentrifugation and directly suspended in a RIPA buffer. Treated cells were washed three times with cold PBS and lysed in a $100 \mu \mathrm{L} /$ well RIPA buffer containing $1 \mathrm{mM}$ PMSF (Solarbio, P0100, Beijing, China) and phosphatase inhibitors (Roche, 4906845001, Penzberg, Germany). Lysed cells were centrifuged and supernatants were transferred into fresh $1.5 \mathrm{~mL}$ centrifuge tubes. Total protein concentrations were determined by the BCA assay (Vazyme, Nanjing, China). All samples were mixed with a $4 \times$ SDS loading buffer. After boiling, each sample $(20 \mu \mathrm{g})$ was subjected to $12 \%$ SDS-PAGE in running buffer at $90 \mathrm{~V}$ for 2 
h. Proteins were electro-transferred to PVDF membranes at $260 \mathrm{~mA}$ for $2 \mathrm{~h}$. PVDF membranes were incubated for $1 \mathrm{~h}$ at room temperature in TBST containing 5\% skimmed milk power. Membranes were incubated at $37^{\circ} \mathrm{C}$ for $2 \mathrm{~h}$ or $4^{\circ} \mathrm{C}$ overnight following primary antibodies [anti-TGFBR2 1:1000, Cat. No. 66636-1-Ig; anti-SMAD4, 1:1000, Cat. No. 10231-1-AP; anti-NR5A1 (SF1), 1:200, Cat. No. 18658-1-AP; anti-Beta actin, 1:2000, Cat. No.20536-1-AP (Proteintech, Wuhan, China); anti-SMAD3 (1:1000, BA4559, BOSTER, Wuhan, China), and anti-phospho-SMAD3 (Phospho-S423/S425) antibodies (1:800, 13370, $\mathrm{SAB})$ ]. After washing three times with TBST, membranes were labeled for $1 \mathrm{~h}$ at room temperature with HRP-conjugated Affinipure Goat Anti-Rat IgG (H + L) (1:2000, Cat. No. SA00001-15, Proteintech, Wuhan, China) antibodies. Protein bands were detected using a chemiluminescence reagent (ECL; Millipore, Billerica, MA, USA) and visualized on an imaging system. Protein bands were analyzed using ImageJ software (ImageJ 1.48V).

\subsection{Chromatin Immunoprecipitation (ChIP)-PCR Assay}

ChIP assays were performed using ChIP assay kits (Beyotime, P2078, Shanghai, China) according to the manufacturer's protocol. Cells were treated in $1 \%$ methanol at $37^{\circ} \mathrm{C}$ for $10 \mathrm{~min}$ and glycine was added to stop the reaction. After washing with cold PBS (×3), cells were lysed with SDS lysis buffer and ultrasound fragmentation assays were used to obtain 300-500 bp DNA fragments. The ChIP dilution buffer was added to produce ultrasound products. SF1-antibodies (Rabbit mAb \#12800, CST) or control IgG were added at $4{ }^{\circ} \mathrm{C}$ overnight. DNA was purified using DNA extraction kits. Primers for ChIP assays are listed in Supplementary Table S1.

\subsection{Dual Luciferase Assays}

After $36 \mathrm{~h}$ transfection, HEK293T cells were washed in PBS and lysed. Relative luciferase activity was measured using dual luciferase assay kits according to the manufacturer's protocols (E1910, Promega, Madison, WI, USA).

\subsection{Apoptosis Assays}

GC apoptosis was assessed using Annexin V-FITC/PI apoptosis detection kits (A211, vazyme, Nanjing, China) according to the manufacturer's protocols. Fluorescence activated cell sorting (FACS) was used to detect GC apoptosis. Early apoptotic cells were stained with Annexin V-FITC and late apoptotic cells were stained with propidium iodide (PI). The apoptotic rates of GCs were calculated and analyzed using Flowjo software (v7.6, Stanford University, Stanford, CA, USA).

\subsection{Cell Proliferation Assays}

GC proliferation assays were performed using BeyoClick EdU cell proliferation kits (Beyotime, Shanghai, China). Cells were cultured in media containing EdU-488 for $12 \mathrm{~h}$ and fixed with $4 \%$ paraformaldehyde for $15 \mathrm{~min}$ at room temperature. Cells were permeabilized in $0.3 \%$ Triton X-100 for $15 \mathrm{~min}$ at room temperature and click additive solution was used to detect EdU. Hoechst 33342 $(5 \mu \mathrm{g} / \mathrm{mL})$ was used to stain cell nuclei. EdU-488 positive cells were detected on an inverted fluorescence microscope (AMG EVOS, Mill Creek, WA, USA).

\subsection{Statistical Analysis}

Experiments for each group were repeated at least three times, data are the means \pm SEM. The GraphPad Prism 6 Software was used to perform statistical analysis. A Spearman's rank correlation coefficient was used in correlation analysis. A two-tailed Student's $t$-test was used for groups comparisons. Three or more groups were compared using one-way analysis of variance and Turkey's test. $p$-value $<0.05$ and $p$-value $<0.01$ were considered as significant and extremely significant differences. 


\section{Results}

\section{1. miR-202-5p Was Highly Expressed in Growing Follicles}

In previous studies, EVs were isolated from goat ovary follicular fluid and EVs-miRNAs were also identified. Heatmap revealed differential expression profiles of EV-miRNAs from small follicular follicles (SFF) and large follicular follicles (LFF) (Figure 1A), that revealed alterations in miRNA levels in the EVs during ovarian follicle development. We found that miR-202-5p was highly expressed in LFF-EVs compared to SFF-EVs (Figure 1B). To further explore the expression of miR-202-5p in ovary follicles, ovarian cells were separated and sorted based on follicle diameter. Realtime-PCR analysis showed that miR-202-5p was highly expressed in GCs in large growth follicles (Figure 1C). MiR-202-5p was also enriched in cumulus cells as opposed to naked-oocytes (Figure 1C). These results suggest that miR-202-5p is functional in the somatic cells of goat ovaries during follicular growth and may regulate oocyte maturation.
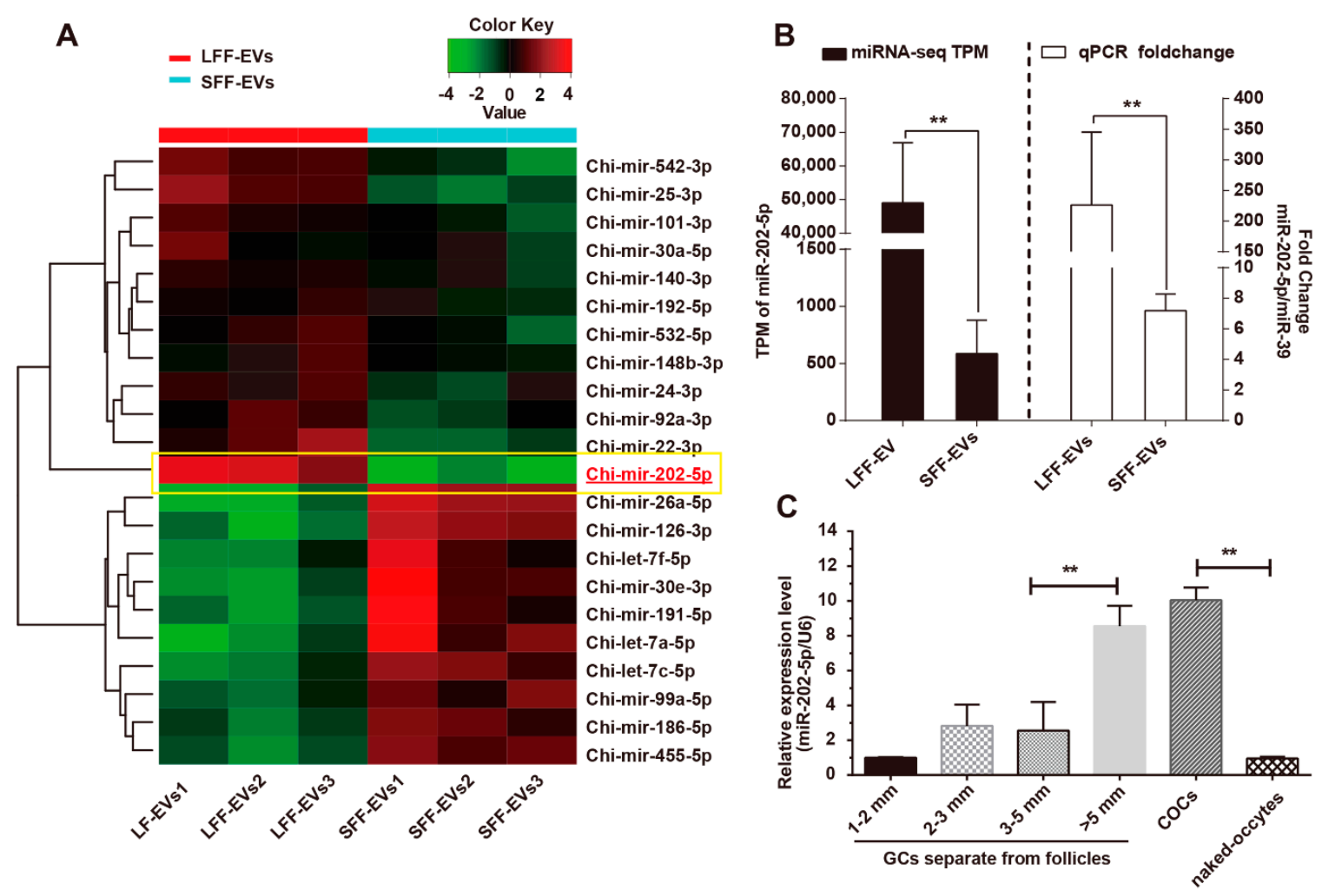

Figure 1. MiR-202-5p is highly expressed in large goat follicles. (A) Heatmap of microRNA (miRNA) expression between the large follicular fluid- extracellular vesicles (LFF-EVs) and the small follicular fluid- extracellular vesicles (SFF-EVs). (B) qPCR revealed the high levels of miR-202-5p in LFF-EVs, miR-39 was used as an external control. (C) Relative expression of miR-202-5p in granulosa cells (GCs), cumulus-oocyte-complex (COCs), and naked-oocytes. Samples are a minimum of three independent repeats. Values are normalized to U6 controls. Bars indicate the mean \pm SEM of three independent replicates; ${ }^{* *} p<0.01$.

\section{2. miR-202-5p Induces GC Apoptosis and Suppresses GC Proliferation In Vitro}

To further investigate the biological functions of miR-202-5p in GCs, miR-202-5p mimics or inhibitors were transfected into cultured GCs in vitro. FACS analysis showed that the rates of GC apoptosis increased after transfection with miR-202-5p mimics compared to NC, whilst inhibiting the expression of miR-202-5p in GCs decreased cell apoptosis rates compared to NC transfections (Figure 2A). In addition, RT-PCR analysis showed that the pro-apoptotic gene $B A X$ was highly 
expressed in miR-202-5p overexpressed GCs compared to cells transfected with NC mimics (Figure 2B and Figure S1). Inhibiting miR-202-5p downregulated $B A X$ expression whilst $B c l 2$ expression increased (Figure 2C and Figure S1). Furthermore, the effects of miR-202-5p on GCs proliferation was verified using EdU assays. Fluorescence analysis suggested that the overexpression of miR-202-5p suppressed GC proliferation $48 \mathrm{~h}$ post transfection (Figure 2D). qPCRs further showed that miR-202-5p inhibits the expression of Cyclin D, Notch2, and PCNA which were associated with cell proliferation (Figure 2E). In contrast, the inhibition of miR-202-5p promoted GC proliferation in vitro (Figure 2D) and increased the relative genes mRNA expression (Figure 2F). Taken together, these results indicate that miR-202-5p induces cell apoptosis and suppresses the proliferation of goat GCs in vitro.

A

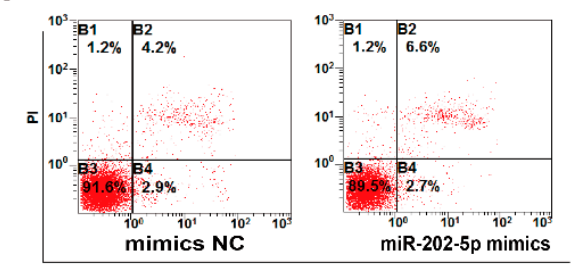

Annexin V-FTIC

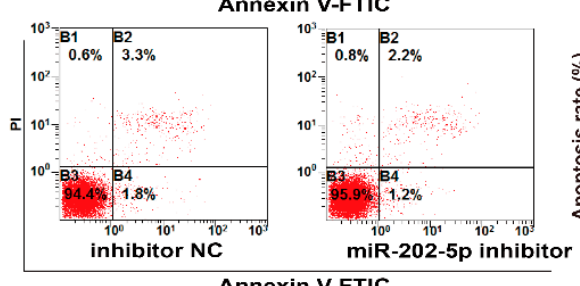

Annexin V-FTIC
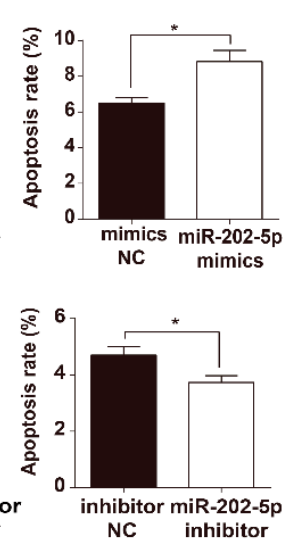

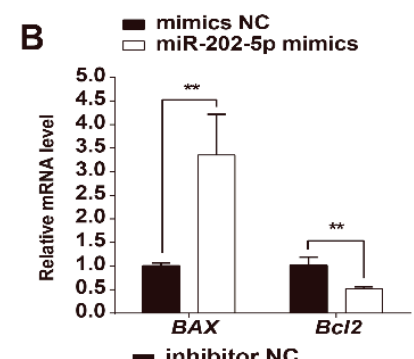

C

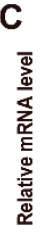

- inhibitor NC
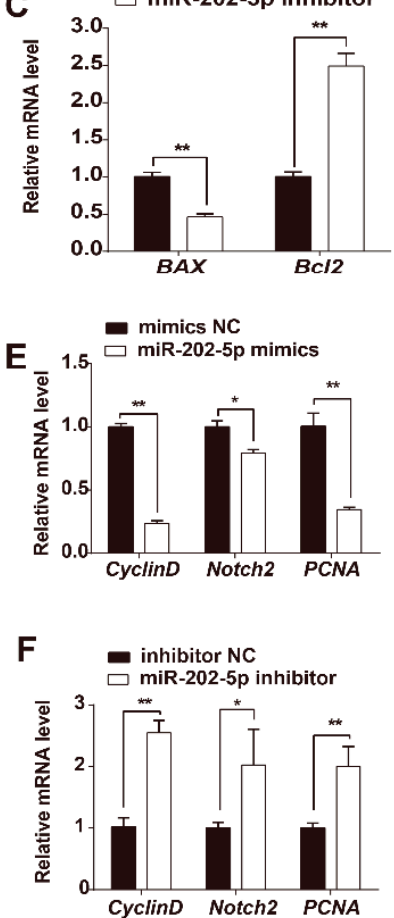

Cyclind Notch2 PCNA
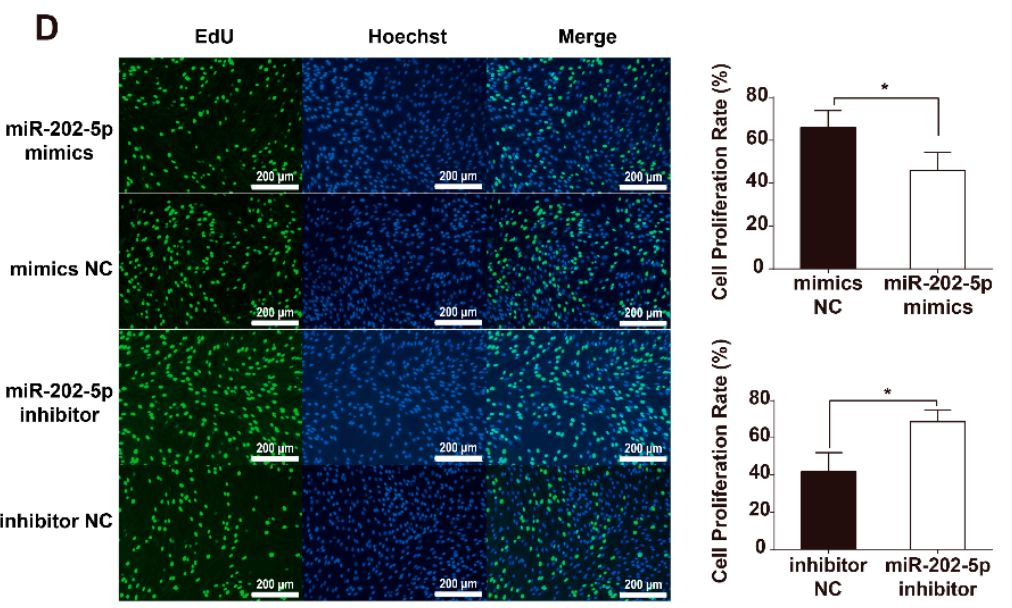

Figure 2. MiR-202-5p induces GC apoptosis and suppresses GC proliferation. (A) miR-202-5p induces cell apoptosis. GCs were treated with miR-202-5p mimics or miR-202-5p inhibitors and mimics negative control (NC) or inhibitor NC. Cell apoptosis were measured by Fluorescence activated cell sorting (FACS) and apoptotic rates were calculated. (B,C) mRNA levels of BAX and Bcl2 detected by qPCR. (D) GC proliferation assessed via EdU assays. Cells were cultured in EdU-488 reagent after transfection with miR-202-5p mimics or miR-202-5p inhibitors and mimics NC or inhibitor NC. EdU-488 represents proliferative cells; blue Hoechst 33342 staining showing total cell numbers, scale bar $=200 \mu \mathrm{m} .(\mathbf{E}, \mathbf{F})$ mRNA levels of CyclinD, Notch2, and PCNA were analyzed by qPCR. All samples were measured from at least three independent experiments. GAPDH was used as an internal control for qPCRs. Bars indicate the mean \pm SEM of three independent replicates; ${ }^{*} p<0.05,{ }^{* *} p<0.01$. 


\section{3. miR-202-5p Binds and Downregulates TGF $\beta R 2$ mRNA Expression in GCs}

To further understand the function of miR-202-5p, we evaluated its cellular targets. Based on three miRNA target databases (miRTarBase, miRDB, and TargetScan7), nine genes were considered (Figure 3A). Among these, TGF $\beta R 1$ and TGF $\beta R 2$ were most relevant to follicles development. In addition, bioinformatics showed that miR-202-5p targets TGF $\beta R 2$ in vertebrates (Figure $3 \mathrm{~B}$ ) and identified the existence of three multiple putative miR-202-5p binding sites within the TGF $\beta R 23^{\prime}$-UTR of goats (Figure 3B). To further confirm that miR-202-5p directly binds to TGF $\beta R 23^{\prime}$-UTR, luciferase reporter vectors expressing three miR-202-5p binding sites in the TGF $\beta R 23^{\prime}$-UTR or mutated binding sites were transfected and relative luciferase activity was assessed (Figure 3C). The relative luciferase activity of all three wildtype reporters was significantly reduced in cells expressing miR-202-5p mimics compared to NC mimics, whilst mutant 3 '-UTR constructs remained unaffected (Figure 3D). To investigate whether miR-202-5p regulates the expression of TGF $\beta R 2$ in goat GCs, miR-202-5p mimics or inhibitors were transfected into cultured goat GCs. The overexpression of miR-202-5p significantly decreased both mRNA and protein expression of TGF $\beta R 2$ (Figure 3E,F), whilst inhibiting miR-202-5p had no significant effects on TGF $\beta R 2$ expression (Figure 3E,F). TGF $\beta R 1$ was also predicted as a target of miR-202-5p. However, neither miR-202-5p overexpression nor silencing in goat GCs altered the levels of TGF $\beta R 1$ (Figure 3E). Taken together, these results demonstrate that miR-202-5p directly regulates TGF $\beta R 2$ expression in goat GCs through binding to the TGF $\beta 223^{\prime}$-UTR.

A

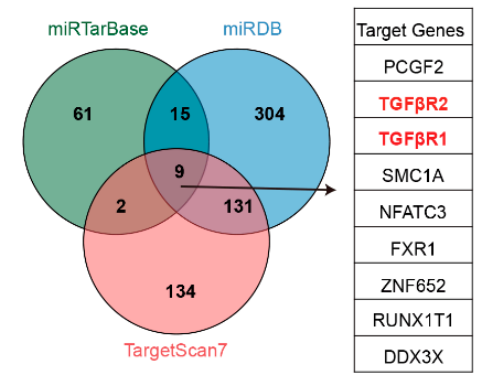

C

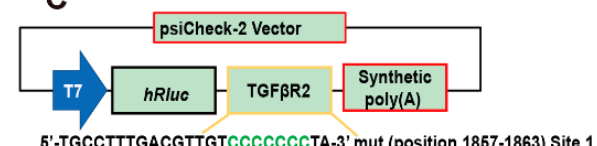

5'-TGCCTTTGACGTTGTCCCCCCCTA-3' mut (position 1857-1863) Site 1 MUT 5'-ATGAGCTTTAATCCTCGAGATGGA-3' mut (position 3296-3302) Site 2 5'-ATACTCATGTATTAAAGGGGGGT-3' mut (position 3889-3896) Site 3

5' -GCCUUUGACGUUGUCAUAGGAUA-3' UTR (position 1857-1863) Slte 1 WT 5' -GAGCUUUAAUCCUCCAUAGGAAA-3' UTR (position 3296-3302) Site 2 5 ' -UACUCAUGUAUUAAAAUAGGAAU-3' UTR (position 3889-3896) Site 3

3'-guUUCUUCAUAUACGUAUCCUU -6' Chi-miR-202-5p

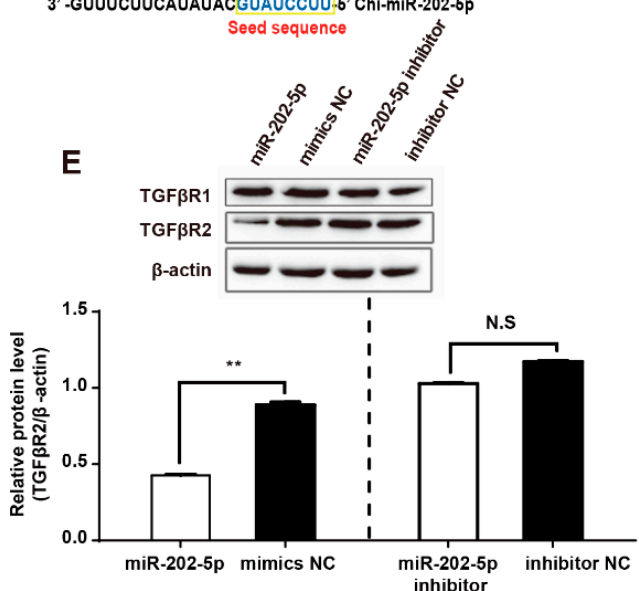

B

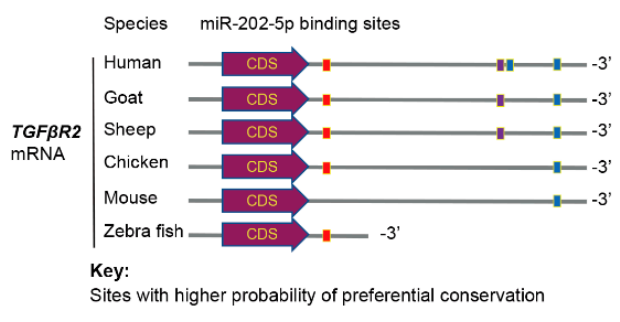

8mer 7mer-m8 7mer-A1

non-canonical

D
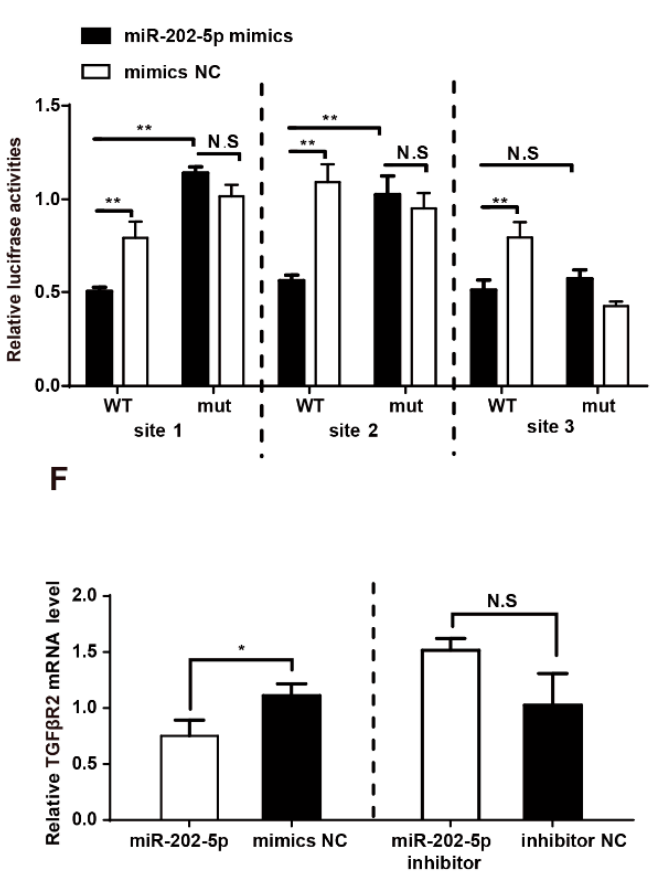

Figure 3. TGF $\beta R 2$ is a direct target of miR-202-5p. (A) Targets of miR-202-5p were predicted using three miRNA databases. Nine overlapping genes are shown. (B) TGF $\beta R 2$ is a target of miR-202-5p 
in different species, rectangles indicated the binding sites of miR-202-5p. (C) Schematic illustrating the design of luciferase reporters with three miR-202-5p binding sites in wildtype TGF $\beta R 23^{\prime} \mathrm{UTR}$ (WT) or mutant TGF $\beta R 2$ 3'UTR (mut). (D) TGF $\beta R 2$ 3'UTR or its mutant luciferase reporter vectors were cotransfected with miR-202-5p mimics (or negative control) into HEK293T cells. Cells were lysed $48 \mathrm{~h}$ post-transfection and assessed for relative luciferase activities. (E) Western blotting (WB) was used to analyze the expression of TGF $\beta R 1$ and TGF $\beta R 2$. (F) TGF $\beta R 2$ mRNA levels were detected in GCs transfected with miR-202-5p mimics, inhibitors, mimics NC or inhibitor NC. Experiments were performed on a minimum of three occasions. Bars indicate the mean \pm SEM of three independent replicates; ${ }^{*} p<0.05,{ }^{* *} p<0.01$, N.S.: Not significant.

\section{4. miR-202-5p Inhibits TGF- $\beta / S M A D$ Signaling in GCs}

TGF $\beta R 2$ is a canonical reporter of the TGF- $\beta$ signaling pathway that regulates downstream SMAD3 and p-SMAD3 expression levels. Next, we investigated whether miR-202-5p to influence GC apoptosis and/or TGF- $\beta / S M A D$ signaling via targets TGF $\beta 2$. SMAD3 and $p$-SMAD3 protein levels were detected in GCs cotransfected with pcDNA3.1-TGF $\beta R 2$ and miR-202-5p mimics. The results showed that TGF $\beta R 2$ could rescue the apoptosis of GCs mediated by miR-202-5p (Figure 4A), whilst GCs transfected with TGF $\beta R 2$-siRNA showed increased rates of apoptosis (Figure 4B). WB analysis of the proteins downstream of TGF- $\beta$ showed that overexpressing miR-202-5p dramatically decreased p-SMAD3 (Phospho-S423/S425) levels in GCs. TGF $\beta$ R2 overexpression in GCs prevented the loss of p-SMAD3 and increased p-SMAD3/SMAD3 levels (Figure 4C). Reducing the expression of TGF $\beta$ R2 inhibited the miR-202-5p inhibitor-mediated enhancement of p-SMAD3 and decreased p-SMAD3/SMAD3 levels (Figure 4D). These findings suggest that miR-202-5p downregulates TGF $\beta R 2$ expression to modulate TGF- $\beta /$ SMAD signaling in goat GCs.

\subsection{SF1 Promotes miR-202 and CYP19A1 Expression through Binding to Their Promoter Regions}

To understand the mechanism(s) through which miR-202-5p is upregulated during follicular development, we focused on the transcriptional regulation and promoter regions. We noted that SF1 acts as a transcriptional factor for both miR-202 and CYP19A1 in several studies [11,23,24]. To define the relationship between SF1 and miR-202 and CYP19A1 in goat ovaries. GCs and FF were separated for RNA extraction and E2 detection, respectively. A total of 22 large follicular follicles were dissected from goat ovaries and semi-quantitative RT-PCR was used to assess gene expression. The relative mRNA level of SF1 in the large follicles significantly and positively correlated with both miR-202-5p $(r=0.5626, p=0.0018)$ (Figure 5A, left) and CYP19A1 ( $r=0.5754, p=0.0099)$ (Figure 5A, middle) expression. As predicted, CYP19A1 expression positively correlated with E2 levels $(r=0.7941$, $p<0.0001$ ) (Figure 5B, left), whilst SF1 also significantly and positively correlated with E2 release in goat GCs $(r=0.6485, p=0.0011)$ (Figure $5 \mathrm{~B}$, middle). We further observed a positive correlation between miR-202-5p expression and CYP19A1 expression $(r=0.5632, p=0.0121)$ (Figure 5A, right) and E2 release $(r=0.452, p=0.0454)$ (Figure $5 \mathrm{~B}$, right) in goat ovarian follicles. These results suggested that miR-202-5p is a potential marker for follicle development.

To further confirm the ability of SF1 to regulate the transcription of miR-202 and CYP19A1, we cultured GCs and transfected pcDNA3.1-SF1 or SF1-siRNA in vitro. The mRNA levels of miR-202-5p were significantly higher in GCs transfected with pcDNA3.1-SF1 compared to pcDNA3.1 and were suppressed following SF1 silencing in GCs (Figure 5C). As expected, CYP19A1 expression was enhanced by the overexpression of SF1, and downregulated following SF1 silencing in cultured GCs (Figure 5D). Next, we focused on the transcriptional regulation of miR-202 and CYP19A1 and their promoter regions. We obtained the sequences of these promoter regions containing nuclear receptor elements (NRE) of goat CYP19A1 (CCAAGGTCA, -241 -249 nt) and miR-202 (CCAAGGTCT, -259 -267 nt). A SF1-0.1 binding sites in miR-202 and CYP19A1 have been reported. CYP19A1 or pri-miR-202 promoter luciferase reporters with wildtype or mutated NREs were generated and co-transfected with pcDNA3.1-SF1 into GCs. We observed an increase in the activity of the wildtype promoter in 
cell expressing CYP19A1 and miR-202 (Figure 5E). Meanwhile, the relative luciferase activity in GCs expression of the mutated SF1 binding sites decreased compared with wildtype promoters (Figure 5E). ChIP-PCR assays were performed to explore the relationship between SF1 and CYP19A1 or miR-202 promoters in vivo. The immunoreactive signals of SF1 were more intense than IgG negative controls (Figure 5F). These data suggest that SF1 is a transcription factor for both CYP19A1 and miR-202. This highlights the association of SF1 with estrogen release and the regulation of miR-202 and CYP19A1 expression through direct binding to their promoters in goat GCs in vivo and in vitro.
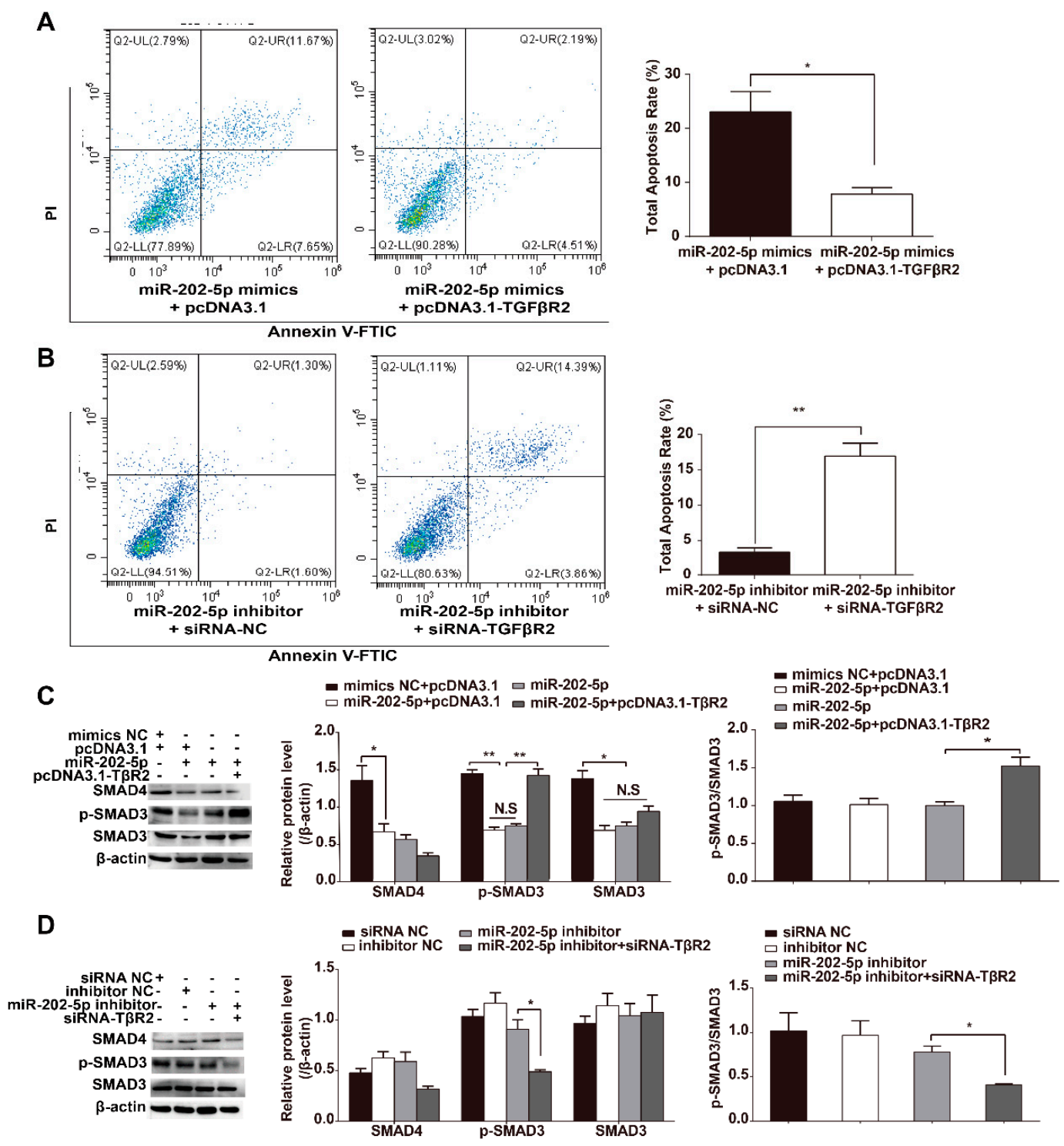

Figure 4. MiR-202-5p functionally targets TGF $\beta R 2$ to regulate GC apoptosis through canonical TGF- $\beta / S M A D$ signaling. Overexpression of TGF $\beta R 2$ rescues cell apoptosis in response to miR-202-5p mimics (A). TGF $\beta R 2$ silencing induces apoptosis in GCs transfected with miR-202-5p inhibitors (B). Cell apoptosis was assessed via FACS ((A,B) left panels) and positive rates were calculated ((A,B) right panels). (C,D) GCs were transfected with the small interfering RNAs (siRNAs) or plasmid vectors and protein levels were analyzed by WB. GCs were cotransfected with miR-202-5p mimics and pcDNA3.1-TGF $\beta R 2$ (T $\beta R 2$ ) or miR-202-5p inhibitor and TGF $\beta R 2$-siRNA. Relative protein levels ((C,D) middle panels) and p-SMAD3/SMAD3 ((C,D) right panel) expression were calculated. Each experiment was repeated on a minimum of three occasions. Bars indicate the mean \pm SEM of three independent replicates; ${ }^{*} p<0.05,{ }^{* *} p<0.01$, N.S.: Not significant. 


\section{6. miR-202-5p Mediates SF1 Regulation of the Canonical TGF- $\beta / S M A D$ Signaling Pathway}

As SF1 enhances miR-202 expression and miR-202-5p targets TGF $\beta$ 22in GCs, we investigated the mechanisms through which SF1 regulates canonical TGF- $\beta$ /SMAD signaling in GCs. qPCR confirmed that SF1 overexpression decreased the mRNA expression of TGF $\beta R 2$ in GCs (Figure 6A). Similarly, WB showed that SF1 decreased TGF $\beta$ R2 protein levels in cultured GCs, confirming its ability to negatively regulate TGF $\beta$ R2 expression (Figure 6B). To further confirm these findings, we cotransfected miR-202-5p inhibitors with pcDNA3.1-SF1 and miR-202-5p mimics with SF1 specific-siRNAs into goat GCs. The results showed that miR-202-5p inhibitor rescued the SF1-mediated decrease in TGF $\beta$ 2 and p-SMAD3 (Phospho-S423/S425) levels (Figure 6B). In contrast, the overexpression of miR-202-5p inhibited the SF1 specific-siRNA increase in TGFßR2 and p-SMAD3 (Phospho-S423/S425) protein expression (Figure $6 \mathrm{C}$ ). These results demonstrated that SF1 negatively regulates TGF- $\beta / S M A D$ signaling through miR-202-5p.

A

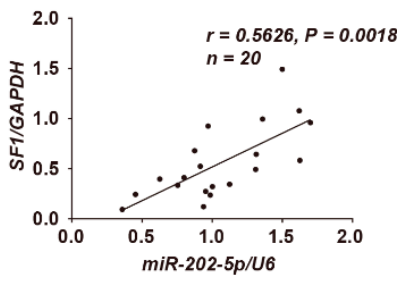

B

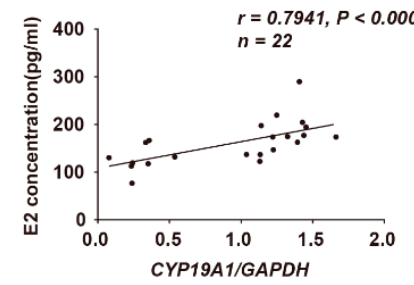

C
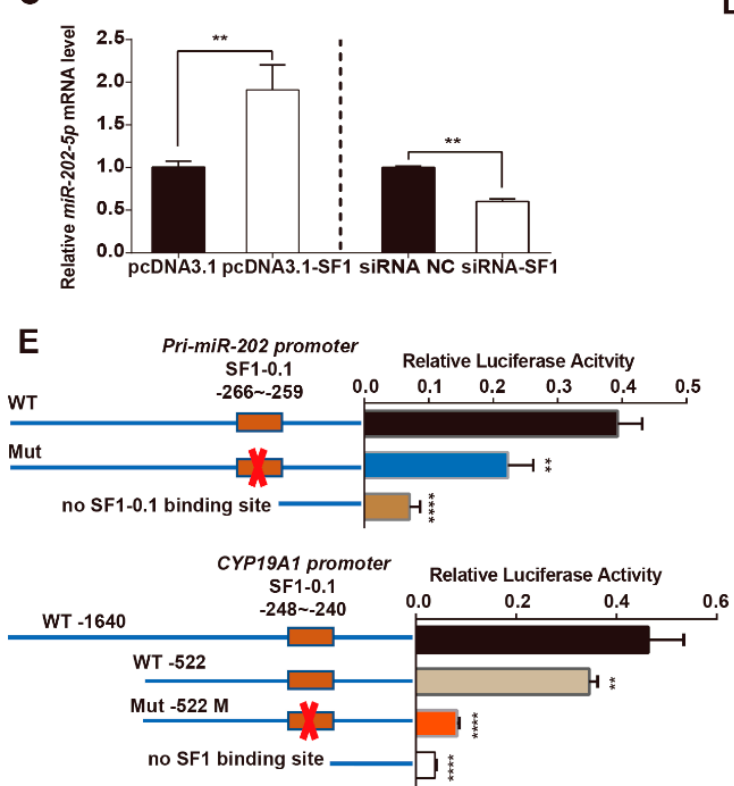
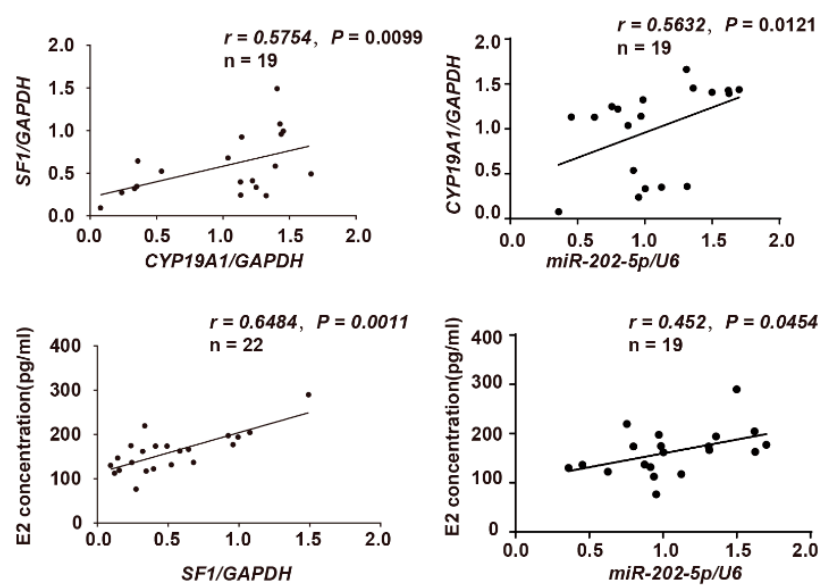

D

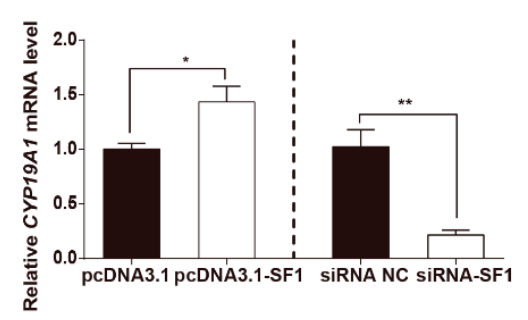

$\mathbf{F}$

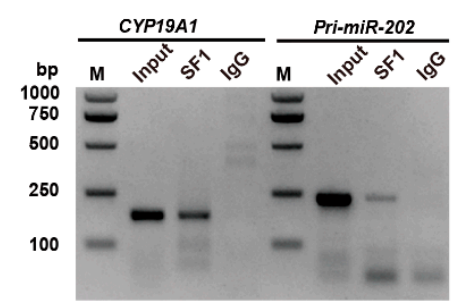

Figure 5. Steroidogenic Factor 1 (SF1) regulates both miR-202-5p and CYP19A1 expression and is associated with estrogen release. (A) Correlation between SF1 and miR-202-5p and CYP19A1. U6 and GAPDH were used as references for miRNA and mRNA expression, respectively. (B) Correlation between $\mathrm{E} 2$ in the follicular fluid and the relative mRNA expression of goat GCs. (C,D) Goat GCs 
were cotransfected with pcDNA3.1-SF1, pcDNA3.1 vector, siRNA-NC and SF1-siRNA, and total RNA was extracted $48 \mathrm{~h}$ post-transfection. mRNA levels of miR-202-5p and CYP19A1 were detected by qPCR. (E) SF1 regulates both miR-202 and CYP19A1 promoter activities. HEK293T cells were cotransfected with pcDNA-3.1-SF1 and reporter vectors harboring wildtype or mutant promoters. Renilla and firefly luciferase were assessed and relative luciferase activity was calculated. (F) Chromatin immunoprecipitation (ChIP) assays to detect SF1 binding to pri-miR-202 and CYP19A1 promoters. Experiments were repeated three times. Correlation analysis was performed using Spearman's rank correlation coefficients. Bars indicate the mean \pm SEM of three independent replicates; ${ }^{*} p<0.05$, ${ }^{* *} p<0.01,{ }^{* * * *} p<0.0001$.

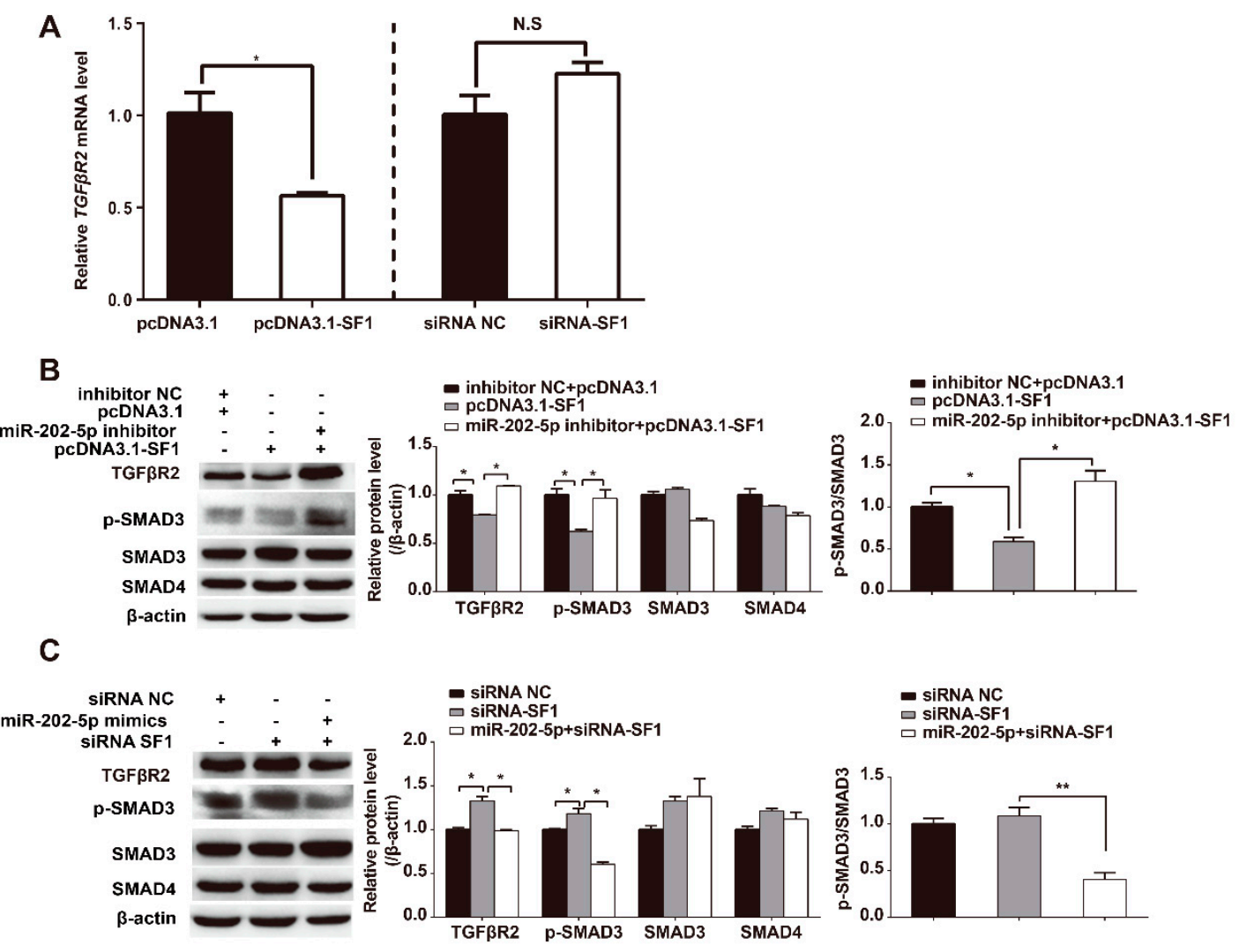

Figure 6. MiR-202-5p mediates the SF1 regulation of canonical TGF- $\beta$ signaling pathway. (A) SF1 regulates TGF $\beta R 2$ mRNA expression in GCs. Cells were transfected with pcDNA3.1-SF1 or SF1-siRNA. mRNAs were quantified by qPCR. (B) pcDNA3.1-SF1 and miR-202-5p inhibitors were cotransfected into GCs and protein levels were analyzed by WB. (C) SF1-siRNA and miR-202-5p mimics were cotransfected into GCs and protein levels were analyzed by WB. Experiments were repeated three times. Bars indicate the mean \pm SEM of three independent replicates; ${ }^{*} p<0.05,{ }^{* *} p<0.01$, N.S.: Not significant.

\section{Discussion}

MiRNAs regulate an array of physiological processes through the post-transcriptional regulation of gene expression. In this study, we identified miR-202-5p as a highly expressed miRNA in the GCs of goat large ovary follicles and further explored its role in GC apoptosis via TGF- $\beta / S M A D$ signaling. We further identified SF1 as a common transcriptional factor that promotes both miR-202 and CYP19A1 expression in GCs.

Our data showed that miR-202-5p was highly expressed in goat GCs during ovarian follicle growth, suggesting its functionality in pre-ovulation follicles. In ruminants, miR-202 shows restricted expression in bovine ovaries, whilst its expression increased in large healthy follicles, particularly in GCs [6]. Furthermore, we found that miR-202-5p positively correlated with CYP19A1 expression in goat ovarian follicles. CYP19A1 catalyzes the conversion of androgens to estrogens, thought to 
be the rate-limiting step during estrogen biosynthesis [23]. This showed a very important role in animal ovarian development. CYP19A1 expression was also restricted to large antral healthy follicles and pre-ovulatory follicles in mature animal ovaries [6,24]. This indicated a relationship between miR-202-5p and CYP19A1 and suggested a potential role for miR-202-5p in E2 release and follicle development. The expression of miR-202-5p in the GCs of larger follicles was higher than that of small follicles and naked-oocytes in goat ovaries. MiR-202 could therefore be considered as a candidate miRNA with potentially important functions in animal reproduction.

MiRNAs function by binding to the mRNA of target genes. In this study, TGF $\beta R 2$ was identified as a functional target of miR-202-5p and overexpressing miR-202-5p induced GC apoptosis through inactivating TGF- $\beta / S M A D$ signaling through the degradation of TGF $\beta R 2$ transcription. TGF $\beta R 2$ is a transmembrane receptor of the TGF- $\beta / S M A D$ signaling that induces SMAD2/3 activity [25]. The downregulation of phospho-SMAD2/3 is pro-apoptotic. Herein, the expression of p-SMAD3 was significantly reduced in goat GCs following treatment with miR-202-5p mimics or TGF $\beta R 2$-siRNA. SMAD3 activity could be rescued by the overexpression of TGF $\beta R 2$. This indicated that miR-202-5p suppresses TGF- $\beta /$ SMAD signaling in apoptotic GCs. However, we observed no significant changes in the levels of TGF $\beta R 2$ and p-SMAD3 in GCs treated with miR-202-5p inhibitors. It is likely that the low levels of endogenous miR-202-5p in GCs in vitro was unaffected by TGF $\beta R 2$ expression. Studies have demonstrated the ability of several miRNAs to suppress TGF $\beta$ R2 expression and induce cell apoptosis via inactivating TGF $\beta R 2$-dependent TGF- $\beta /$ SMAD signaling in GCs [26-28]. In mammalian ovaries, miRNAs that regulate members of the TGF- $\beta$ signaling pathway have been identified in atretic follicles. For example, miR-224 and miR-26b regulate GC apoptosis through their effects on SMAD4, a key factor of the canonical TGF- $\beta$ signaling [29,30]. miR- 425 downregulates TGF $\beta R 2$, leading to GCs apoptosis in porcine ovaries [27]. Studies on miRNAs and TGF- $\beta$ signaling pathways in ovarian follicles highlight its importance in follicle atresia. This study provides new evidence of the miRNA regulation of goat GC genes and indicates that miR-202-5p regulates TGF- $\beta$ signaling.

To our knowledge, TGFBR2 is the only TGF $\beta$ receptor able to bind all the TGF $\beta$ ligands and elicit functional signaling to cells. TGF $\beta R 2$ activates TGF/activin and BMP/GDF pathways into cells through SMAD2/3 and SMAD1/5/8, respectively [31]. Furthermore, in vitro, FSH increases the levels of TGFB1, TGFBR2, SMAD2, SMAD3, and SMAD4 in mouse GCs. The levels of phospho-SMAD3, but not phospho-SMAD2, also increased in response to FSH, demonstrating the continual activation of TGF $\beta$ signaling [32]. SMAD3 in GCs enhances the upregulation of TGF $\beta R 2$ expression to promote cell proliferation through facilitating the effects of TGF $\beta$ on GCs [33]. Here, the apoptosis of goat GCs was enhanced by the overexpression of miR-202-5p and TGF $\beta 22$ specific small interfering RNAs, whilst phosphor-SMAD3 was also attenuated. This suggests that TGF $\beta$ signaling was mainly activated by mediating TGF $\beta R 2$ in goat GCs. In ovarian cells, TGF $\beta 22$ is expressed throughout all stages of follicular development, including primary follicles in the embryonic phase, pre-ovulation follicles, and cells of the luteal corpus [34,35]. Moreover, TGF $\beta$ R2-specific depletion in GCs using FSHR-Cre mice led to a weak maintenance of oocyte meiotic arrest within large antral follicles. TGF $\beta R 2$ depletion also impaired follicle development, ovulation, and female fertility [32].

MiR-202 is an intronic RNA that participates in multiple cellular physiological processes, including cell growth, apoptosis, migration, and invasion [36-38]. The expression of miR-202-5p is regulated by SF1 or SRY (Sex-Determining Region Y)-Box 9 (SOX9) during mouse testis differentiation [11]. In this study, we observed a positive relationship between $m i R-202-5 p$ and SF1 and CYP19A1 in goat follicles. Characterization of the putative miR-202 promoter in vitro suggested that SF1 transactivates $m i R-202$ at specific genomic regions, with mutations of specific SF1 binding sites ameliorating this transactivation. In addition, we found that SF1 binds to the CYP19A1 promoter region to enhance CYP19A1 expression and E2 concentrations in goat. These results fully describe the positive correlation between miR-202-5p and CYP19A1 gene in goat GCs. CYP19A1 contains multiple promoters, whilst the ovary-specific expression patterns of aromatase are controlled by type II promoters (PII) that reside within the immediate $5^{\prime}$ flanking regions of the translational start 
site [39]. SF1 was shown to regulate CYP19A1 transcription through its binding to the nuclear receptor motifs within the PII promoter region [40,41]. In this study, an additional SF1 motif was verified in the sequence of goat CYP19A1 gene, also termed SF1-0.1 in mice [11]. SF1 as a key functional regulator of ovary development [42], acts at multiple levels of the reproductive axis [43]. SF1 silencing indicated its vital role during adrenal and gonadal development [44]. The ovaries of SF1-silenced mice were hypoplastic and sterile and showed reduced numbers of oocytes and lacked corpora lutea [45]. SF1 belongs to the nuclear receptor subfamily that requires a cAMP-response element-binding protein (CREB)-regulated transcription coactivator (CRTC2) and calcineurin to regulate to CYP19A1 expression in rat ovarian GCs [46]. Moreover, TGF- $\beta 1$ was confirmed to enhance SF1 (a nuclear receptor NR5A subfamily member) and LRH-1 (liver receptor homolog 1) expression in GCs treated with FSH [46]. However, in human adrenocortical cells, TGF- $\beta 1$ suppresses endogenous SF1 levels and the overexpression of SMAD3 inhibits SF1 binding to the CYP17 promotor [47]. Additionally, SF1 was required for TGF- $\beta 3$-induced CYP19A1 expression and E2 release, whilst TGF- $\beta 3$ enhanced the binding of SF1 to the endogenous ovary-specific CYP19A1 type II promoter [48]. The relationship between SF1 and TGF- $\beta$ signaling is therefore complex and requires further studies in steroidogenesis cells. In addition, the overexpression SF1 could suppress TGFBR2 expression through miR-202-5p in GCs. This indicated the ability of SF1 to regulate the downstream targets of TGF- $\beta 1$. Taken together, these results suggest the presence of a negative feedback loop between SF1 and TGF- $\beta$ signaling mediated by miR-202-5p in GCs.

\section{Conclusions}

Our results provide an alternative regulatory mechanism of miR-202-5p mediated apoptosis in the GCs of goat ovaries and identified SF1 as a transcription factor that promotes both miR-202 and CYP19A1 expression (Figure 7). Our findings suggest that TGF $\beta R 2$ expression was suppressed by miR-202-5p and SF1 in cultured GCs in vitro, providing a rationale for the gene-miRNA-gene axis in ovarian follicles. Collectively, these data reveal the existence of a new regulatory axis in goat ovaries through canonical TGF- $\beta /$ SMAD signaling during follicular development.

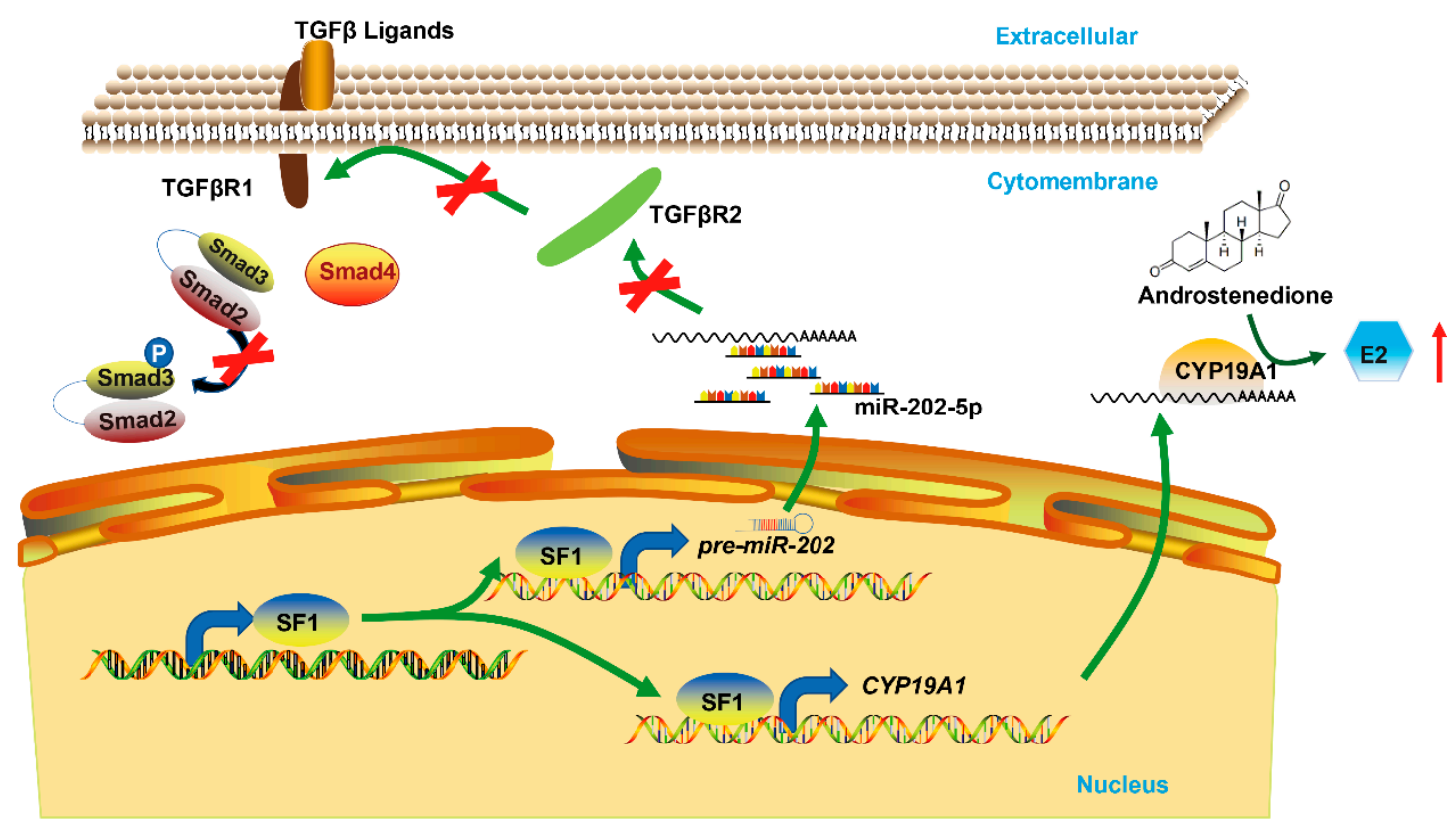

Figure 7. Schematic of miR-202-5p-mediated SF1 regulation of the canonical TGF- $\beta$ signaling pathway in GCs. 
Supplementary Materials: The following are available online at http://www.mdpi.com/2073-4409/9/2/445/s1, Figure S1: miR-202-5p induces GCs apoptosis; Table S1: The primers are used in this study; Table S2: The sequences of siRNA are used in this study.

Author Contributions: Q.D., M.J., and Y.C. designed the research; Q.D., M.J., J.L., Y.W. (Yaoyue Wang), and Y.W. (Ying Wang) performed the experiments; Q.D., P.K., Y.Y., and X.W. analyzed the data and wrote the manuscript. All authors have read and agreed to the published version of the manuscript.

Funding: This work was funded by the National Key Research and Development Program of China (2018YFD0501905), the Natural Science Foundation of China (31872332, 31772571), and China Agriculture Research System (CARS-39-12).

Conflicts of Interest: The authors declare no conflict of interest.

Ethics Statement: All studies were conducted in accordance with the guidelines approved by the Experimental Animal Committee of the Northwest A\&F University, Yangling, China (Approval ID: 2014ZX08008-002).

Data Availability Statement: Qiang Ding had full access to all the data in this study and takes the responsibility for the integrity of the data and the accuracy of the data analysis. The data that support the findings of this study are available from the corresponding author upon reasonable request.

\section{References}

1. Jolly, P.D. Morphological evidence of apoptosis and the prevalence of apoptotic versus mitotic cells in the membrana granulosa of ovarian follicles during spontaneous and induced atresia in ewes. Boil. Reprod. 1997, 56, 837-846. [CrossRef] [PubMed]

2. Matsuda, F.; Inoue, N.; Manabe, N.; Ohkura, S. Follicular growth and atresia in mammalian ovaries: Regulation by survival and death of granulosa cells. J. Reprod. Dev. 2012, 58, 44-50. [CrossRef] [PubMed]

3. Terenina, E.; Fabre, S.; Bonnet, A.; Monniaux, D.; Robert-Granie, C.; SanCristobal, M.; Sarry, J.; Vignoles, F.; Gondret, F.; Monget, P.; et al. Differentially expressed genes and gene networks involved in pig ovarian follicular atresia. Physiol. Genom. 2017, 49, 67-80. [CrossRef] [PubMed]

4. Manabe, N.; Goto, Y.; Matsuda-Minehata, F.; Inoue, N.; Maeda, A.; Sakamaki, K.; Miyano, T. Regulation mechanism of selective atresia in porcine follicles: Regulation of granulosa cell apoptosis during atresia. J. Reprod. Dev. 2004, 50, 493-514. [CrossRef] [PubMed]

5. Hughes, F.M.; Gorospe, W.C. Biochemical Identification of Apoptosis (Programmed Cell Death) in Granulosa Cells: Evidence for a Potential Mechanism Underlying Follicular Atresia*. Endocrinology 1991, 129, $2415-2422$. [CrossRef]

6. Sontakke, S.D.; Mohammed, B.T.; McNeilly, A.S.; Donadeu, F.X. Characterization of microRNAs differentially expressed during bovine follicle development. Reproduction 2014, 148, 271-283. [CrossRef]

7. Navakanitworakul, R.; Hung, W.-T.; Gunewardena, S.; Davis, J.S.; Chotigeat, W.; Christenson, L.K. Characterization and Small RNA Content of Extracellular Vesicles in Follicular Fluid of Developing Bovine Antral Follicles. Sci. Rep. 2016. [CrossRef]

8. Liu, J.; Yao, W.; Yao, Y.; Du, X.; Zhou, J.; Ma, B.; Liu, H.; Li, Q.; Pan, Z. MiR-92a inhibits porcine ovarian granulosa cell apoptosis by targetingSmad7gene. Febs Lett. 2014, 588, 4497-4503. [CrossRef]

9. Liu, J.; Li, X.; Yao, Y.; Li, Q.; Pan, Z.; Li, Q. miR-1275 controls granulosa cell apoptosis and estradiol synthesis by impairing LRH-1/CYP19A1 axis. Biochim. Et Biophys. Acta (Bba) - Bioenerg. 2018, 1861, 246-257. [CrossRef]

10. Zhou, J.; Liu, J.; Pan, Z.; Du, X.; Li, X.; Ma, B.; Yao, W.; Li, Q.; Liu, H. The let-7g microRNA promotes follicular granulosa cell apoptosis by targeting transforming growth factor- $\beta$ type 1 receptor. Mol. Cell. Endocrinol. 2015, 409, 103-112. [CrossRef]

11. Wainwright, E.N.; Jorgensen, J.S.; Kim, Y.; Truong, V.; Bagheri-Fam, S.; Davidson, T.; Svingen, T.; Fernandez-Valverde, S.L.; McClelland, K.S.; Taft, R.J.; et al. Sox9 regulates microrna mir-202-5p/3p expression during mouse testis differentiation1. Biol. Reprod 2013, 89, 1-12. [CrossRef] [PubMed]

12. Chen, J.; Cai, T.; Zheng, C.; Lin, X.; Wang, G.; Liao, S.; Wang, X.; Gan, H.; Zhang, D.; Hu, X. Microrna-202 maintains spermatogonial stem cells by inhibiting cell cycle regulators and rna binding proteins. Nucleic Acids Res. 2017, 45, 4142-4157. [CrossRef] [PubMed]

13. Dabaja, A.A.; Mielnik, A.; Robinson, B.D.; Wosnitzer, M.S.; Schlegel, P.N.; Paduch, D.A. Possible germ cell-sertoli cell interactions are critical for establishing appropriate expression levels for the sertoli cell-specific microrna, mir-202-5p, in human testis. Basic Clin. Androl. 2015, 25, 1-8. [CrossRef] [PubMed] 
14. Michalak, P.; Malone, J.H. Testis-derived microRNA profiles of African clawed frogs (Xenopus) and their sterile hybrids. Genom. 2008, 91, 158-164. [CrossRef] [PubMed]

15. Armisen, J.; Gilchrist, M.J.; Wilczynska, A.; Standart, N.; Miska, E.A. Abundant and dynamically expressed mirnas, pirnas, and other small rnas in the vertebrate xenopus tropicalis. Genome Res. 2009, 19, 1766-1775. [CrossRef]

16. Zhang, J.; Liu, W.; Jin, Y.; Jia, P.; Jia, K.; Yi, M. Mir-202-5p is a novel germ plasm-specific microrna in zebrafish. Sci. Rep. 2017. [CrossRef]

17. Gay, S.; Bugeon, J.; Bouchareb, A.; Henry, L.; Delahaye, C.; Legeai, F.; Montfort, J.; Le Cam, A.; Siegel, A.; Bobe, J.; et al. MiR-202 controls female fecundity by regulating medaka oogenesis. PloS Genet. 2018. [CrossRef]

18. Donadeu, F.X.; Sontakke, S.D.; Ioannidis, J. And MicroRNA indicators of follicular steroidogenesis. Reprod. Fertil. Dev. 2016. [CrossRef]

19. Donadeu, F.; Schauer, S. Differential miRNA expression between equine ovulatory and anovulatory follicles. Domest. Anim. Endocrinol. 2013, 45, 122-125. [CrossRef]

20. Schmittgen, T.D.; Livak, K.J. Analyzing real-time PCR data by the comparative CT method. Nat. Protoc. 2008, 3, 1101-1108. [CrossRef]

21. Liang, Z.; Jiahao, C.; Zhizhong, L.; Xianxin, L.; Xueda, H.; Yi, H.; Xiaokun, Z.; Chaozhao, L.; Yong, W.; Liang, S. Integrated profiling of micrornas and mrnas: Micrornas located on xq27.3 associate with clear cell renal cell carcinoma. PLOS ONE 2010. [CrossRef]

22. Wang, L.; Feng, Z.; Wang, X.; Wang, X.; Zhang, X. DEGseq: An R package for identifying differentially expressed genes from RNA-seq data. Bioinformatics 2010, 26, 136-138. [CrossRef] [PubMed]

23. Thompson, E.A.J.; Siiteri, P.K. The involvement of human placental microsomal cytochrome P-450 in aromatization. J. Boil. Chem. 1974, 249, 5373-5378.

24. Guigon, C.J.; Mazaud, S.; Forest, M.G.; Brailly-Tabard, S.; Coudouel, N.; Magre, S. Unaltered Development of the Initial Follicular Waves and Normal Pubertal Onset in Female Rats after Neonatal Deletion of the Follicular Reserve. Endocrinology 2003, 144, 3651-3662. [CrossRef] [PubMed]

25. Li, Q.; Agno, J.E.; Edson, M.A.; Nagaraja, A.K.; Nagashima, T.; Matzuk, M.M. Transforming Growth Factor $\beta$ Receptor Type 1 Is Essential for Female Reproductive Tract Integrity and Function. PLoS Genet. 2011. [CrossRef] [PubMed]

26. Du, X.; Pan, Z.; Li, Q.; Liu, H.; Li, Q. SMAD4 feedback regulates the canonical TGF- $\beta$ signaling pathway to control granulosa cell apoptosis. Cell Death Dis. 2018. [CrossRef]

27. Du, X.; Zhang, L.; Li, X.; Pan, Z.; Liu, H.; Li, Q. TGF- $\beta$ signaling controls FSHR signaling-reduced ovarian granulosa cell apoptosis through the SMAD4/miR-143 axis. Cell Death Dis. 2016. [CrossRef]

28. Yang, S.; Wang, S.; Luo, A.; Ding, T.; Lai, Z.; Shen, W.; Ma, X.; Cao, C.; Shi, L.; Jiang, J.; et al. Expression Patterns and Regulatory Functions of MicroRNAs During the Initiation of Primordial Follicle Development in the Neonatal Mouse Ovary1. Boil. Reprod. 2013. [CrossRef]

29. Yao, G.; Yin, M.; Lian, J.; Tian, H.; Liu, L.; Li, X.; Sun, F. MicroRNA-224 Is Involved in Transforming Growth Factor- $\beta$-Mediated Mouse Granulosa Cell Proliferation and Granulosa Cell Function by Targeting Smad4. Mol. Endocrinol. 2010, 24, 540-551. [CrossRef]

30. Liu, J.; Du, X.; Zhou, J.; Pan, Z.; Liu, H.; Li, Q. Microrna-26b functions as a proapoptotic factor in porcine follicular granulosa cells by targeting sma-and mad-related protein 4. Biol. Reprod. 2014. [CrossRef]

31. Moustakas, A.; Heldin, C.-H. The regulation of TGF signal transduction. Development 2009, 136, 3699-3714. [CrossRef]

32. Yang, J.; Zhang, Y.; Xu, X.; Li, J.; Yuan, F.; Bo, S.; Qiao, J.; Xia, G.; Su, Y.; Zhang, M. Transforming growth factor $\beta$ is involved in maintaining oocyte meiotic arrest by promoting natriuretic peptide type $C$ expression in mouse granulosa cells. Cell Death Dis. 2019. [CrossRef]

33. Li, Y.; Jin, Y.; Liu, Y.; Shen, C.; Dong, J.; Xu, J. SMAD3 regulates the diverse functions of rat granulosa cells relating to the FSHR/PKA signaling pathway. Reproduction 2013, 146, 169-179. [CrossRef]

34. Schilling, B.; Yeh, J. Expression of transforming growth factor (TGF)- $\beta 1$, TGF- $\beta 2$, and TGF- $\beta 3$ and of type I and II TGF- $\beta$ receptors during the development of the human fetal ovary. Fertil. Steril. 1999, 72, 147-153. [CrossRef] 
35. Roy, S.K.; Kole, A.R. Ovarian transforming growth factor-beta (TGF-beta) receptors: In-vitro effects of follicle stimulating hormone, epidermal growth factor and TGF-beta on receptor expression in human preantral follicles. Mol. Hum. Reprod. 1998, 4, 207-214. [CrossRef]

36. Mody, H.R.; Hung, S.W.; Pathak, R.K.; Griffin, J.; Cruz-Monserrate, Z.; Govindarajan, R. miR-202 Diminishes TGF $\beta$

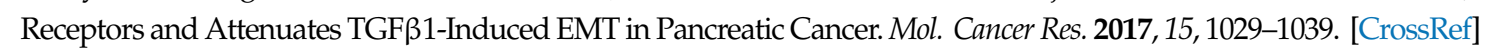

37. Yang, J.; Fan, B.; Zhao, Y.; Fang, J. MicroRNA-202 inhibits cell proliferation, migration and invasion of glioma by directly targeting metadherin. Oncol. Rep. 2017, 38, 1670-1678. [CrossRef]

38. Zhang, S.; Cai, J.; Xie, W.; Luo, H.; Yang, F. miR-202 suppresses prostate cancer growth and metastasis by targeting PIK3CA. Exp. Med. 2018, 16, 1499-1504. [CrossRef]

39. Jenkins, C.; Michael, D.; Mahendroo, M.; Simpson, E. Exon-specific northern analysis and rapid amplification of cDNA ends (RACE) reveal that the proximal promoter II (PII) is responsible for aromatase cytochrome P450 (CYP19) expression in human ovary. Mol. Cell. Endocrinol. 1993, 97, 1-6. [CrossRef]

40. Rice, D.A.; Mouw, A.R.; Bogerd, A.M.; Parker, K.L. A shared promoter element regulates the expression of three steroidogenic enzymes. Mol. Endocrinol. 1991, 5, 1552-1561. [CrossRef]

41. Morohashi, K.; Honda, S.; Inomata, Y.; Handa, H.; Omura, T. A common trans-acting factor, Ad4-binding protein, to the promoters of steroidogenic P-450s. J. Boil. Chem. 1992, 267, 17913-17919.

42. Parker, K.L.; Schimmer, B.P. Steroidogenic factor 1: A key determinant of endocrine development and function. Endocr. Rev. 1997, 18, 361-377. [CrossRef] [PubMed]

43. Parker, K.L. Steroidogenic Factor 1: An Essential Mediator of Endocrine Development. Recent Prog. Horm. Res. 2002, 57, 19-36. [CrossRef] [PubMed]

44. Schimmer, B.P.; White, P.C. Minireview: Steroidogenic factor 1: Its roles in differentiation, development, and disease. Mol. Endocrinol. 2010, 24, 1322-1337. [CrossRef]

45. Pelusi, C.; Ikeda, Y.; Zubair, M.; Parker, K.L. Impaired follicle development and infertility in female mice lacking steroidogenic factor 1 in ovarian granulosa cells. Boil. Reprod. 2008, 79, 1074-1083. [CrossRef]

46. Lai, W.; Yeh, Y.; Fang, W.; Wu, L.; Harada, N.; Wang, P.; Ke, F.; Lee, W.; Hwang, J. Calcineurin and crtc2 mediate fsh and tgf $\beta 1$ upregulation of cyp19a1 and nr5a in ovary granulosa cells. J. Mol. Endocrinol. 2014, 53, 259-270. [CrossRef]

47. Derebecka-Holysz, N.; Lehmann, T.P.; Holysz, M.; Trzeciak, W.H. SMAD3 inhibits SF-1-dependent activation of the CYP17 promoter in H295R cells. Mol. Cell. Biochem. 2007, 307, 65-71. [CrossRef]

48. Ning, L.; Yinglei, X.; Yimeng, Y.; Guidong, Y.; Hui, T.; Guishuan, W.; Jie, L.; Yong, W.; Fei, S. Steroidogenic factor-1 is required for tgf-beta3-mediated 17beta-estradiol synthesis in mouse ovarian granulosa cells. Endocrinology 2011, 152, 3213-3225. 